\title{
The Effects of Different Applications on Creativity Regarding Academic Achievement: A Meta-Analysis
}

\author{
Şenel Elald1 ${ }^{1}$, Veli Batd $1^{2}$ \\ ${ }^{1}$ Cumhuriyet University, Sivas, Turkey \\ ${ }^{2}$ Kilis 7 Aralık University, Kilis, Turkey \\ Correspondence: Şenel Elald1, Cumhuriyet University, Sivas, Turkey
}

Received: September 21, 2015 Accepted: October 9, 2015 Online Published: October 15, 2015

doi:10.11114/jets.v4i1.1097

URL: http://dx.doi.org/10.11114/jets.v4i1.1097

\begin{abstract}
In this study, through a meta-analysis of 20 studies, it is aimed to compare the effectiveness of various forms of learning methods including creativity based learning, problem based learning, and differentiated instruction on creativity in terms of the academic achievement of students and to find out other study characteristics, related to the effectiveness of creativity. Studies including the pretest-posttest control group model and collected from national and international arena between the years 2000 to 2015 were chosen. In this context, 20 studies that met inclusion criteria were analyzed under three themes: creativity based learning, problem based learning, and differentiated instruction by using Comprehensive Meta- Analysis and the MetaWin statistical program. In addition, other studies having effectiveness on creativity were categorized as "method" and "approach" and their effect sizes were calculated separately. The effect size values of academic achievement scores in each theme were found to be respectively $0.850,1.560$, and 0.729 which were significant and at a large level in the first two themes; at a medium level in the third theme according to the classification of Thalheimer and Cook. The results indicated that different applications had positive effects on academic achievement.
\end{abstract}

Keywords: meta-analysis, creative-based learning, problem-based learning, differentiated instruction, academic achievement

\section{Introduction}

The subject of creativity as a divine, mystical, or spiritual phenomenon has fascinated human beings throughout history. However, creativity is a relatively new field of scientific research. Primary researches have been conducted about creativity by Guilford, the chairman of the American Psychology Association, in1950's (Demirci, 2007). Until this time, creativity had been a "neglected area" of scientific interest (Petrowski, 2000, p. 305). According to Petrowski (2000), psychology's relative disinterest in creativity is because of being perceived as spiritual, rather than scientific, subject matter. Although the neglect of this subject by psychologists, Guilford envisaged scientific research on creativity and offered several explanations for its apparent absence in today's literature (Gardner, 1993).

Although creativity is generally regarded as an innate, natural ability or talent, it withstands a "universally acceptable definition" (Jones, 1972, p. 5). As Fishkin (1999) explains, creativity as a "fascinating combination of phenomena" cannot be captured within a "single definition" (p. 5). Most generally accepted definitions of creativity consist of two major criteria: novelty and appropriateness (Atkinson, 2000; Mayer, 1999; Starko, 2005). In line with these criteria, Dineen, Samuel, and Livesey (2005) suggested creativity as "a process producing an outcome that is novel/original and appropriate/valuable" (p. 155). Similarly, according to Kaufman \& Sternberg (2010), creative ideas must be high quality and represent something different, new, or innovative. The concept of creativity first appeared in the English language by referring to a person, process, or product considered to be new and useful, imaginative and productive (Bleakley, 2004). In addition to person, product, and process categories, the fourth category called as press which refers to the relationship between human beings and their socio-cultural environment is still commonly used to frame new concepts of creativity (Richards, 1999; Runco, 2004).

Since creativity has been perceived as an essential criterion in education, it can be taught in the classroom. Treffinger (1985) and Feldhusen and Treffinger (1986) argued that a feasible objective for education is enhancing the creative thinking and problem solving of students. According to Cronin (1989), creative thinking skills are no different than any 
other skill and can be learned and practiced. In order to develop creative skills, one must be provided with practice, motivation, involvement, interaction with teachers and other students, and structure (Torrance, 1986). Since the concept of problem-solving is closely associated with both creativity and innovation (Gordon, 2011; Nickerson, 1999; Saiz \& Rivas, 2011), in a creative process, "the thinker finds a problem or issue worthy of being addressed, generates ideas for solving it, and evaluates those ideas" (Starko, 2005, p. 192). In other words, creative patterns include acts of comparing, contrasting, visualizing, interpreting, and problem solving (Scholl, 2005). For some researchers, such as Newall, Shaw, \& Simon (1962), creative thinking is a subset or "special class" (p. 66) of problem-solving while others argue that creative thinking and problem solving are one in the same (Feldhusen \& Teffinger, 1986 Guilford, 1964). As overlapping concepts, in problem solving stage "students need to think creatively when a definitive answer for a problem does not exist; when prior experience is not necessarily helpful; and when rules for solving the problem are not available" (Antonietti,1997, p. 75). Fundamental elements of creative and problem solving activities are also needed to encourage creativity in differentiated instruction which promotes multiple options for acquiring, processing, and expressing knowledge, so that all students can learn effectively according to their needs (Tomlinson, 1995); think critically and creatively about what they learned and extend their understanding (Tomlinson \& Edison, 2003). Therefore, by emphasizing creativity, student thinking can be shifted beyond memorization towards higher-level thinking such as analyzing, synthesizing, and evaluating (Kiener \& Ahuna, 2011) in all instruction methods.

The present meta-analytic study focuses on the comparison of the effectiveness of various forms of learning methods including creativity-based learning (CBL), problem-based learning (PBL), and differentiated instruction (DI) on creativity in terms of the achievement of students, and therefore this study aims to synthesize recent research to signify in which applications creativity is more correlated with academic achievement. To fulfill the purpose of this study, two key research questions were addressed:

1. To what extent are the different applications including CBL, PBL and DI effective on creativity considering academic achievement of students?

2. To what extent are other studies categorized as "method" and "approach" effective on creativity considering academic achievement of students?

\section{Meta-analysis Methodology}

The current study employed meta-analysis method which is a quantitative and formal study design used to assess previous research studies systematically and to derive conclusions about that body of research (Haidich, 2010). While reaching a general conclusion, the results of different studies concerning the same subject but collected independently from each other are put together and re-analyzed to specify the level of students (Glass, 1976).

\subsection{Literature Search Procedure}

A comprehensive literature search of studies written between 2000 and 2015 was conducted by using national and international educational databases [Proquest Dissertations \& Theses Global, Google Scholar, the Higher Education Council National Thesis and Dissertation Center, Ebscohost-Eric (National Academic Network and Information Center)]. The keywords used to conduct the search included: "creative-based learning", "problem-based learning", "differentiated instruction", "creativity" both English and Turkish as the key learning methods which were combined with "creativity" and "academic achievement". This procedure resulted in the identification of 20 studies. Of this total, 19 were generated from theses and 1 was from articles.

\subsection{Introducing a Set of Inclusion Criteria}

In line with the following inclusion criteria which were established for selecting studies, 20 of these 330 studies met the criteria and were included in the analysis.

1. Only studies that used experimental and control groups (pretest-posttest control group model) were included (i.e., no single-subject studies were included). The focus of the studies was on comparing the academic achievement of a group of students who were instructed using one of the various forms of learning methods including CBL, PBL, and DI to their counterparts who were instructed using traditional lecture-based instruction in terms of promoting creativity.

2. Studies must have reported sample sizes, means and standard deviations, or t-test values, F-test values, or p-values, so that effect sizes could be calculated (Cooper \& Hedges, 1994).

3. Studies could have been performed in any country, but the report had to be available in English or Turkish.

4. Studies had to have taken place from 2000 to 2015.

\subsection{Coding of Studies}

To identify and explain each study in detail, studies needed to be coded in three phases. In the $1^{\text {st }}$ phase of coding called "study identity" which was related to describing the studies, the study features were categorized as name of study, year of publication, types of publication (published or unpublished), and author information. Some information related to 
course type, grade levels, and the duration of implementation (weeks) were presented in the $2^{\text {nd }}$ phase of coding. Sample sizes, means and standard deviation values used in the meta- analysis calculation were given in the $3^{\text {rd }}$ phase of coding called "study data".

\subsection{Identifying Variables}

Meta-analysis has also dependent and independent variables as in any experimental and correlational studies.

\subsubsection{Independent Variable (s)}

The independent variables are study characteristics in a meta-analysis. These study characteristics which were coded in the coding form of this study were related to publication histories (publication type, publication year, author information), grade levels, duration of implementation and study data (sample sizes, mean and standard deviation values).

\subsubsection{Dependent Variable (s)}

The dependent variable was academic achievement of students for this meta-analysis. In order to yield effect sizes for the dependent variable of academic achievement, various experimental settings and tasks were used in the studies.

\subsection{Statistical Analysis}

The data were analyzed statistically using the Comprehensive Meta-Analysis (CMA) statistical program and the MetaWin program. The study effect meta-analysis method which includes calculations of the differences between the mean scores of experimental and control groups (Hunter, \& Schmidt, 1990: cited in Acar, 2011) was applied to analyze the data.

Effect size is a way of quantifying the size of difference between the experimental and control groups (Coe, 2002). In the present study, Hedges'd formula was used for the estimation of effect size (Hedges \& Olkin, 1985), defined as the difference between experimental and comparison groups means divided by the standard deviation (Cooper \& Hedges, 1994). In addition, in order to detect the total heterogeneity of a sample, a Q statistic which is distributed as a chi-square distribution with $\mathrm{k}-1$ degrees of freedom where $\mathrm{k}$ is the number of effect sizes (Hedges \& Olkin, 1985) was used. The k-1 degree of freedom chi-square $(\chi 2)$ heterogeneity test was defined and suggested as the most common test approach to determine heterogeneity by Cochran (Higgins et al. 2003). In order to determine the effect sizes, fixed effect models (FEM) and random effects models (REM) were used. While under the fixed-effect model, there is a common effect size that underlies all the studies in the analysis, under the random-effects model, it is possible that all studies share a common effect size, but it is also possible that the effect size varies from study to study (Borenstein, et.al. 2009). Finally, all the statistical data included in the analysis were converted into a common effect size and interpreted using Thalheimer and Cook (2002) guidelines which suggest that $-0,15 \leqslant$ is a negligible effect size, $0,15 \leqslant$ is a small effect size, $0,40 \leqslant$ is a medium effect size, $0,75 \leqslant$ is a large effect size, $1,10 \leqslant$ is a very large effect size, and $1,45 \leqslant$ is a huge effect size.Furthermore, in order to obtain a certain level of reliability, the research outcomes were calculated by another reader having a Ph.D. and serving as a coder. In order to validate inter-coder reliability of the studies which were involved in the current research, Miles and Huberman's (1994) formula [agreement / (agreement + disagreement) x 100] was carried out and it was calculated as $100 \%$. The result indicated that the reliability between the researchers and coder was very high.

\section{Results}

The number of studies meeting the inclusion criteria of the current study in the synthesis was 20 . Of 20 studies 1 article, $9 \mathrm{PhD}$ theses, 10 master's theses were retained in the analysis with a total sample size of 1089 students. While the experimental group consisted of 549, the control group consisted of 540 students.

To find out the answer of the research question concerning to what extent the different applications including CBL, PBL, and DI are effective on creativity considering academic achievement of students, thematic-based meta-analysis was carried out. Therefore, the findings involving the comparison of the effects of different applications on creativity in terms of academic achievement scores of students to traditional students' scores were given. For this purpose, first, descriptive information belonging to meta-analysis was introduced and then, the effect sizes calculated separately for each subcategory were examined whether the changes occurred for each group or not. In other words, the distribution of homogeneous values, average effect sizes and confidence intervals of the studies included in the current study were calculated in two phases. In the first phase, the applications of CBL, PBL, and DI were thematized under the same title in order to be reached and analyzed more than one studies (Table1). In addition, fail-safe number $\left(\mathrm{F}_{\mathrm{SN})}\right.$ obtained according to Rosenthal's Method (R.'s M) was computed by MetaWin. In the second phase, the effect coefficients $(d)$ of different applications which were conducted by different methods and approaches and therefore, thematized as "Method" and "Approach" were evaluated. 


\subsection{The Results of the Studies Included in Meta-Analysis in Terms of Academic Achievement Scores Which Were Grouped as Thematic-based}

Titles of the studies in terms of the effect of creativity and examined in the scope of meta-analysis were thematized under three groups. The first theme was called " $C B L$ ". The findings of the general effect sizes regarding academic achievement of the studies which were related to the effect of this theme on creativity and included in meta-analysis were given in Table 1 .

As shown in Table 1, according to the results of the studies in the theme of CBL, the standard error was 0.121 and the upper limit for $95 \%$ of the confidence interval was 1.088 while the lower limit was 0.612 and the effect size was 0.850 . It can be stated that the effect size of the model is positive and significant. When the statistical significance was calculated according to the z-test, it was found as 6.876 (p>.05). As a result of the homogenous test, the Q statistical value was calculated as 6.876. In a $95 \%$ significance level from the chi-square table, the critical value of 9.488 and four degrees of freedom are accepted. Since the Q statistical homogeneity test value with four degrees of freedom did not

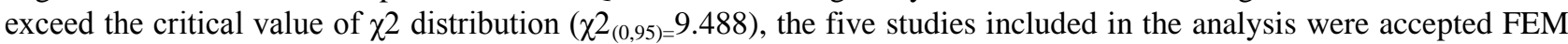
belonging to the homogeneity of distribution of effect sizes. In other words, the distribution of the effect size according to FEM was found to be homogenous.

Table 1. The Distribution of Homogeneous Values, Average Effect Sizes, Confidence Interval and Fail-Safe Number of the Studies Included in Meta-Analysis according to Effect Models

\begin{tabular}{|c|c|c|c|c|c|c|c|c|c|}
\hline \multirow{2}{*}{ THEME } & \multirow{2}{*}{ Model Type } & \multirow{2}{*}{$\mathrm{n}$} & \multirow{2}{*}{$\mathrm{Z}$} & \multirow[b]{2}{*}{$\mathrm{p}$} & \multirow{2}{*}{ Q } & \multirow{2}{*}{$\mathrm{ES}$} & $\mathrm{F}_{\mathrm{SN}}$ & \multicolumn{2}{|c|}{$95 \%$ Confidence Interval } \\
\hline & & & & & & & R.'s M & Lower limit & Upper Limit \\
\hline CBL & FEM & 5 & 7.00 & 0.15145 & 6.876 & 0.850 & 87.0 & 0.612 & 1.088 \\
\hline PB & FEM & 5 & 10.106 & 0.000 & 36.793 & 1.315 & 10 & 1.060 & 1.570 \\
\hline FDL & REM & 5 & 3.859 & 0.30706 & 4.819 & 1.560 & 10. & 0.768 & 2.353 \\
\hline IDI & FEM & 3 & 2.762 & 0.000 & 92.781 & 0.897 & & 0.260 & 1.534 \\
\hline DI & REM & 3 & 0.326 & 0.34837 & 2.117 & 0.729 & 3.4 & -3.659 & 5.117 \\
\hline
\end{tabular}

The distribution of homogeneous value, average effect size and confidence intervals of the five studies which comprise the scores of the studies in the theme of $P B L$ and included in meta-analysis were reported in Table 1. As a result of the analysis carried out with FEM concerning the scores of relevant studies, the standard error was 0.130 and the upper limit for $95 \%$ of the confidence interval was 1.570 while the lower limit was 1.060 and the effect size was 1.315 . As a result of the homogenous test, the Q statistical value was calculated as 36.793. In a 95\% significance level from the chi-square table, four degrees of freedom was found to be 9.488 . Since the $\mathrm{Q}$ statistical value exceeded the critical value of $\chi^{2}$ distribution in 6.314 and four degrees of freedom $\left(\chi_{(0,95)}=9.488\right)$, these five studies were not accepted FEM belonging to the homogeneity of distribution of effect sizes. In other words, it can be said that the distribution of the effect size is heterogeneous. The significance of the Q statistical value and the changes in the effect sizes would be expected from a sampling error (Lipsey \& Wilson 2001). Therefore, as a result of the analysis carried out with REM, the standard error was 0.404 and the upper limit for $95 \%$ of the confidence interval was 2.353 while the lower limit was 0.768 and the effect size was 1.560 . This indicates that the use of PBL has a more positive effect on students' academic achievement than traditional method. As a result of the z-test calculation for the purpose of statistical significance, the analysis can be said not to be statistically significant $(\mathrm{z}=3.859 ; \mathrm{p}>.05)$.

The analysis of the studies in the theme of $D I$ was carried out with FEM and presented in Table 1. Based on this calculation, the standard error was 0.325 and the upper limit for $95 \%$ of the confidence interval was 1.534 while the lower limit was 0.260 and the effect size was 0.897 . As a result of the homogenous test, the Q statistical value was calculated as 92.781. In a 95\% significance level from the chi-square table, two degrees of freedom was found to be 5.991. Therefore, it was observed that the $Q$ statistical value exceeded the critical value of $\chi 2$ distribution in 92.781 and two degrees of freedom $\left(\chi_{(0,95)}=5.991\right)$. As a result of the analysis carried out with REM, the standard error was 0.729 and the upper limit for $95 \%$ of the confidence interval was 5.117 while the lower limit was -3.659 and the effect size was 0.729 and therefore, it can be interpreted that the use of DI has more positive effects on students' academic achievement than traditional method.

Another point considered in the study is to determine a possible publication bias that may occur in meta-analytic studies. Meta-analytic studies mostly include published studies and therefore, since the tendency for journals to only publish studies with statistically significant results, the most commonly assumption that the studies in the meta-analysis accumulate at a certain point generates a problem and may cause doubts about meta-analysis; at this point, in meta-analytic studies related to elimination of the relevant assumption and doubts, how many more studies be included in the analysis in order to reduce significant differences to zero is calculated. Rosenthal (1979) described the number of additional studies that are required as fail-safe number $\left(N_{\mathrm{FS}}\right)$. Fail-safe numbers of each theme taken place in this study were calculated by Metawin program. Fail-safe number of the studies in the theme of $C B L$ was 87; in the theme of $P B L$ 
was 210.1 ; in the theme of $D I$ was 3.4. In the current meta-analytic study, the effect of different applications on creativity was reduced to 0.01 by including more studies as much as fail-safe numbers specified for each theme. In this context, the fail-safe numbers of each theme were all relatively large in the current meta-analysis, suggesting that the results were reliable.

\subsection{The Results of the Studies Included in Meta-analysis in Terms of Academic Achievement Scores Which Were} Grouped as Methods and Approaches

Another aim of this meta-analytic study is to evaluate studies which were not only included in the analysis under the theme of methods and approaches but also they involved in different applications according to the effect coefficients given in Table 2. In the theme of Method, studies including the effects of methods such as Drama-based learning (Kaya, 2006), Discovery learning (Biber, 2006), Teaching with analogy (Sayg1l, 2008), Cooperative learning (Uysal, 2009) on creativity were evaluated while in the theme of Approach, the effects of Project-based learning (Birinci, 2008) and Constructivist learning (Kaya, 2010) environments on creativity considering academic achievement were analyzed. As a result of the analysis, the effect coefficients of every study were evaluated according to the classification of Thalheimer and Cook (2002). However, the existence of outlier values among the average effect size values obtained from studies which were examined for meta-analysis would not enable meta-analysis to reach logical grounds (Hufcutt and Arthur, 1995; Hunter and Schmidt, 1990). In this context, a study the effect coefficient of which was evaluated as outlier value [Bacak, 2008 (d:15.7584)] was excluded from the data set.

Table 2. The Effect Sizes (ES), the Upper Limit Effect Size (ULES) and the Lower Limit Effect Size (LLES) of the Studies Included in Different Applications

\begin{tabular}{lccccccc}
\hline \multicolumn{1}{c}{ Studies } & ES & ULES & LLES & \multicolumn{1}{c}{ Studies } & ES & ULES & LLES \\
\hline Kaya $(2006)_{\mathrm{T} 16}$ & 1.279 & 0.747 & 1.811 & Uysal $(2009)_{\mathrm{T} 32}$ & 0.297 & -0.124 & 0.718 \\
Biber $(2006)_{\mathrm{T} 17}$ & 0.737 & 0.137 & 1.338 & Birinci $(2008)_{\mathrm{T} 22}$ & -0.045 & -0.476 & 0.387 \\
Sayg1l1 $(2008)_{\mathrm{T} 24}$ & 1.592 & 0.787 & 2.396 & Kaya $(2010)_{\mathrm{T} 37}$ & -1.948 & -2.513 & -1.384 \\
\hline
\end{tabular}

Besides the effect sizes of studies including in different applications, the values regarding upper and lower limits of the effect sizes were reported in Table 2. The effect size of different applications for academic achievement in CBL environments can be interpreted as follows: The effect size of the study titled "the effect of using project-based learning in adaptation and development of materials on prospective teachers' critical thinking, creative thinking and scientific process skills" by Birinci (2008) was calculated as insignificant (ES=-0.045). The effect size of another study titled "the effects of the practices based on constructivist learning in teacher education on prospective teachers' problem solving, critical thinking and creative thinking dispositions" by Kaya (2010) was also found insignificant (ES=-1.948). However, while the effect size of the study titled "the effects of Cooperative learning method on the access, achievement, critical thinking and creativity skills of the elementary school fourth-grade students" by Uysal (2009) was low (ES=0.297), the effect size of another study titled "the effects of the method of discovery learning on primary education grade II mathematics students" creativity" by Biber (2006) was medium (ES=0.737). In addition, the study titled "the contribution of drama-based education to creativity process in the third grade elementary students' visual arts courses" by Kaya (2006) had a very large effect size (ES=1.279). Similarly, another study titled "the effect of analogy-enhanced teaching on mathematical success and creative thinking ability of $9^{\text {th }}$ high school students" by Saygill (2008) had also a very large effect size $(\mathrm{ES}=1.279)$. In line with these findings, it can be said that analogy-enhanced teaching is likely to be more effective on students' creativity than the other different applications given above.

\section{Discussion}

This meta-analysis study was aimed to discuss the thematic-based meta-analytical quantitative data related to the effects of different applications including CBL, PBL, and DI on creativity in learning environments and the reflection of these effects to academic achievement of students. It was also aimed to evaluate studies which were not only included in the analysis under the theme of Method and Approach but also they involved in different applications according to effect coefficient values. In this context, first, different applications were discussed under three themes as "CBL, PBL and DI". Then, some different applications were introduced under the themes of "Method" and "Approach". Afterwards, related data were discussed. In other words, the analysis results were compared with the current studies in the literature and the results were interpreted separately. In addition, in order to indicate the reliability of the meta-analysis, fail-safe number was also found and interpreted by calculating the publication bias.

The first theme titled "Creative- based learning" was formed by combining studies related to the effects of applications, taking place in the scope of different applications but based on this title, on students' creativity. In this case, when data obtained from studies examining the effects of CBL environments on students' academic achievement were evaluated by REM, effect size value was found to be 0.850 .This value can be interpreted as at a large level, positive and significant according to the classification of Thalheimer and Cook (2002) and therefore, it can be concluded that related 
applications have very positive effects on academic achievement. This positive and significant result was consistent with the effect coefficients of all studies (Beydemir, 2010; Kadayıfçı, 2008; Karataş Öztürk, 2007; Özcan, 2009; Sak and Öz, 2010) and included in the analysis. In addition, similar results were also consistent with the results of the different studies which were conducted nationally and internationally (Tok, 2008; Wang, 2003) and excluded from the analysis. It can be interpreted that the results obtained from the studies included in the meta-analysis and related to the effects of creativity-based learning applications on academic achievement are quite consistent with those mentioned in the related literature. However, in a master's thesis titled "the effects of creative thinking activities on the creative web design of the elementary school students" by Saç (2011), the achievement scores obtained from website creating by the students participating in the research revealed that while the students of the experimental group were better in general design, there was no difference in terms of creativity. Therefore, it is likely to state that the results of this thesis are not consistent with the present results. In this meta-analytic study, the effect coefficients of the studies (Akay, 2006; Çoban, 2004; Eren, 2011; Kaçar, 2012; Ülger, 2011) related to the effects of problem- based applications comparing academic achievement scores of students on creativity were significantly different. Although the effect coefficients of the studies showed differences between 0.5593 and 3.0215 , all the effect coefficients were positive. However, when the meta-analysis results of the studies in the theme of PBL according to REM were calculated, the standard error was 0.404 and the upper limit for $95 \%$ of the confidence interval was 2.353 . The lower limit was 0.768 and the effect size was 1.560. The results indicated that in favor of PBL, academic achievement scores were better than traditional teaching methods. In addition, the effect size was calculated as at a large level, positive and significant according to the classification of Thalheimer and Cook (2002) and therefore, it can be said the use of the relevant applications in the learning environments had positive effects on academic achievement scores of students. Similar results were obtained from the studies (Çoban, 2004; Kaçar, 2012) in which students taking part in the experiment group were chosen and interviewed in order to determine their views on PBL. Descriptive statistics and content analysis were used in the evaluation of the qualitative data obtained from the interviews. This evaluation revealed that students in the experimental group had positive views on the PBL.

For meta-analysis results of the studies (Batdal Karaduman, 2012; Kaplan Sayı, 2013; Kök, 2012) in the theme of DI-based applications, the standard error was 0.729 and the upper limit for $95 \%$ of the confidence interval was 5.117 while the lower limit was -3.659 and the effect size was 0.729 which was accepted as medium according to the classification of Thalheimer and Cook (2002). The results indicated that in favor of DI, academic achievement scores were better than traditional teaching methods. In other words, the relevant applications had high levels of effectiveness in terms of academic achievement. On the other hand, when the effect coefficients of these three studies analyzed in detail, the effect coefficient of the study conducted by Batdal Karaduman (2012) was calculated as $-3,8625$. As for the effect coefficients of the other studies conducted by Kök (2012) and Kaplan Sayı (2013), they were $d=2.6530 ; d=$ 3.3902 respectively. It is remarkable that the related values were calculated in both negative and positive sense at outlier value levels, but in general the results indicated that DI-based applications increased students' academic achievement scores significantly.

When the effect sizes of different application based studies included in the analysis under the theme of "Method" and "Approach" on academic achievement in creativity based learning environments were calculated, the following effect levels were observed according to the classification of Thalheimer and Cook (2002): insignificant (Birinci, 2008; Kaya, 2010), low (Uysal, 2009), medium (Biber, 2006), and very large (Kaya, 2006; Saygll, 2008). In general, the effect coefficients had positive/ meaningful effects on academic achievement of the related applications. In this context, this result obtained from the studies included in meta-analysis was consistent with the master's theses (Akdal, 2011; Aydın, 2011; Bacak, 2008; Çalışkan, 2006; Kayahan, 2010; Şahintürk, 2012; Yıldız, 2012;Yılmaz, 2006), PhD theses (Aktamış, 2007; Parker, 2008;Tezci, 2002) and articles (Altıntaş, Özdemir \& Kerpiç, 2013; Gündoğan, Arı \&Gönen, 2013; Kim \& Kim, 2010; Naeini \& Masood, 2012) which were conducted nationally and internationally in different years. In addition, the meta-analytic studies performed internationally by Davis (2009) and Feist (1998) had also positive effect sizes.

In conclusion, it is likely to say that studies grouped into three main themes as CBL, PBL and DI and additionally investigated as the effects of different applications on creativity were generally effective on academic achievements of students in teaching environments. Although various databases were searched nationally and internationally related to the effects of different applications on creativity, sufficient numbers of experimental studies were not reached. These results indicate that creativity should be given more importance in teaching environments especially in application dimension. In addition, it is recommended perform more studies related to this subject for future researchers.

\section{References}

(The references marked with an asterisk (*) are used in meta-analysis study.)

Acar, S. (2011). Examining the effect of computer-based education on students' attitude in the fields of Physics, 
Chemistry, Biology and Maths through meta-analysis method.(Unpublished master's thesis). YüzüncüYıl University, Van, Turkey.

*Akay, H. (2006). The examination of the effect of mathematics instruction with problem posing approach on students' academic achievement, problem solving ability and creativity. (Unpublished doctoral dissertation). Gazi University, Ankara, Turkey.

Akdal, D. (2011). The impact of intertextual reading on creative writing skills of 5th grades of students in primary education. (Unpublished master's thesis). Ahi Evran University, Kırşehir, Turkey.

Aktamıs, H. (2007). The effects of scientific process skills on scientific creativity: the example of primary school seventh grade physics. (Unpublished doctoral dissertation). Dokuz Eylül University, İzmir, Turkey.

Altıntaş, E., Özdemir, A. Ş., Kerpiç, A. (2013). The effect of teaching based on the Purdue Model on creative thinking skills of students. Kalem Eğitim ve İnsan Bilimleri Dergisi, 3(1), 187-214.

Antonietti, A. (1997). Unlocking creativity. Educational Leadership, 54(6), 73-75.

Atkinson, S. (2000). Does the need for high levels of performance curtail the development of creativity in design and technology project work? International Journal of Technology and Design Education, 10, 255-281. http://dx.doi.org/10.1023/A:1008904330356

Aydın, Z. (2001). An analysis of the effects of active learning-based activities employed in mathematics classes of the 6th grades on the creative thinking levels and attitudes of students. (Unpublished master's thesis). Gaziantep University, Gaziantep, Turkey.

*Bacak, S. (2008). The effects of the storyline method of the achievement and creativity on the students in primary schools' 5. class in social studies lesson. (Unpublished master's thesis). Celal Bayar University, Manisa, Turkey.

*Batdal, K. G. (2012). The effects of differentiated geometry teaching for fifth grade gifted students on creative thinking, spatial ability level and achievement. (Unpublished doctoral dissertation). Istanbul University, İstanbul, Turkey.

Bayburtlu, B. (2011). The effect of Webquest method on students' ability of creative thinking and the level of motivation. (Unpublished master's thesis). Gazi University, Ankara, Turkey.

*Beydemir, A. (2010). The effect of creative writing approach on writing attitude, creative writing and writing achievement in Turkish classes at fifth grade in primary schools. (Unpublished master's thesis), Pamukkale University, Denizli, Turkey.

*Biber, M. (2006). The effects of the method of discovery learning on primary education grade II mathematics students' creativity. (Unpublished master's thesis). Dokuz Eylül University, İzmir, Turkey.

*Birinci, E. (2008). The effect of using project-based learning in adaptation and development of materials on teacher candidates' critical thinking, creative thinking and scientific-process skills. (Unpublished master's thesis). Karaelmas University, Zonguldak, Turkey.

Bleakley, A. (2004). "Your creativity or mine?" A typology of creativities in higher education and the value of a pluralistic approach. Teaching in Higher Education, 9(4), 463-475. http://dx.doi.org/10.1080/1356251042000252390

Borenstein, M., Hedges, L. V., Higgins, J. P. T., \& Rothstein, H. R. (2009). Introduction to meta-analysis. Chichester: Wiley edition. John Wiley \& Sons. http://dx.doi.org/10.1002/9780470743386

Coe, R. (2002). It's the effect size, stupid: What effect size is and why it is important. Paper presented at the Annual Conference of the British Educational Research Association, University of Exeter, England, 12-14 September 2002.

Cooper, H., \& Hedges, L. V. (Eds.). (1994). Handbook of research synthesis. New York: Russell Sage.

Cronin, L. L. (1989). Creativity in the science classroom. The Science Teacher, 56, 34- 36.

Çalıskan, B. (2006). Increasing creative and critical thinking skills in $7^{\text {th }}$ grades in secondary part of primary school through revitalizing stories. (Unpublished master's thesis). Yıldız Teknik University, Istanbul, Turkey.

*Çoban, B. (2014). The effects of problem based learning to success, creativity and transfer skills of the students. (Unpublished master's thesis). Gazi University, Ankara, Turkey.

Davis, M. A. (2009). Understanding the relationship between mood and creativity: A meta-analysis. Organizational Behavior and Human Decision Processes 108, 25-38. http://dx.doi.org/10.1016/j.obhdp.2008.04.001

Demirci, C. (2007). The effects of the creative approach in science teaching on achievement and attitude. Hacettepe 
University Journal of Education, 32, 65-75.

Dineen, R., Samuel, E., \& Livesey, K. (2005). The promotion of creativity in learners: Theory and practice. Art, Design \& Communication in Higher Education, 4(3), 155-172. http://dx.doi.org/10.1386/adch.4.3.155/1

*Eren, C. D. (2011). The effect of problem based learning (PBL) on critical thinking disposition, concept learning and scientific creative thinking skill in science education. (Unpublished doctoral dissertation). Marmara University, İstanbul, Turkey.

Feist, G. J. (1998). A meta-analysis of personality in scientific and artistic creativity. Personality and social psychology review, 2(4), 290-309. http://dx.doi.org/10.1207/s15327957pspr0204_5

Feldhusen, J. F., \& Treffinger, D. J. (1986). Creative thinking and problem solving in gifted education. Dubuque, IA: Kendall/Hunt.

Fishkin, A. S. (1999). Issues in studying creativity in youth. In A.S. Fishkin, B. Cramond, \& P. Olszewski-Kubilius (Eds.), Investigating creativity in youth: Research and methods (pp. 3-26). Cresskill, New Jersey: Hampton Press.

Gardner, H. (1993). Creating minds: An anatomy of creativity seen through the lives of Freud, Einstein, Picasso, Stravinsky, Eliot, Graham, and Gandhi. New York: Basic Books

Glass, G. V. (1976). Primary, secondary, and meta-analysis of research. Educational Researcher, 5(10), 3-8. http://dx.doi.org/10.3102/0013189X005010003

Gordon, D. (2011). Return to sender. T.H.E. Journal, 38(3), 30-32, 34-35.

Guilford, J. P. (1964). Creative thinking and problem solving. Education Digest, 29, 21-31.

Gündoğan, A., Arı, M., \& Gönen, M. (2013). Dramanın farklı yaş gruplarındaki çocukların yaratıcı hayal güçleri üzerindeki etkisi. Hacettepe University Journal of Education Faculty, 28(2), 206-220.

Haidich, A. B. (2010). Meta-analysis in medical research. Hippokratia, 14(1), $29-37$.

Hedges, L. V., \& Olkin, I. (1985). Statistical methods for meta-analysis. Academic Press, Orlando, FL

Higgins, J. P., Thompson, S. G., Deeks, J. J., \& Altman, D. G. (2003). Measuring inconsistency in meta-analyses. British Medical Journal, 2, 557-560. http://dx.doi.org/10.1136/bmj.327.7414.557

Huffcutt, A. I., \& Arthur, W. Jr. (1995). Development of a new outlier statistic for meta-analytic data. Journal of Applied Psychology, 80(2), 327-334. http://dx.doi.org/10.1037/0021-9010.80.2.327

Hunter, J., \& Schmidt, F. (1990). Methods of meta-analysis: Correcting error and bias in research findings. Beverly Hills CA: Sage.

Jones, T. P. (1972). Creative learning in perspective. London: University of London Press Ltd.

*Kaçar, S. (2012). The effects of problem based learning method integrated visual arts on students' academic achievements, scientific creativities and attitudes towards science teaching with art activities. (Unpublished master's thesis). Dokuz Eylül University, İzmir, Turkey.

*Kadayıfçı, H. (2008). The effect of an instructional model based on creative thinking on students' conceptual understanding of separation of matter subject and their scientific creativity. (Unpublished doctoral dissertation). Gazi University, Ankara, Turkey.

*Kaplan, S. A. (2013). The effect of differentiated foreign language instruction on gifted students' achievment, critical thinking and creativity. (Unpublished doctoral dissertation). İstanbul University, İstanbul, Turkey.

*Karataş, Ö. S. (2007). The effect of the learning approach based on creative thinking upon the creative thinking and problem solving skills of students. Unpublished master's thesis, Osmangazi University, Eskişehir, Turkey.

Kaufman, J. C., \& Sternberg, R. J. (2010). Preface. In J. C. Kaufman \& R. J. Sternberg (Eds.), The Cambridge handbook of creativity (pp. xiii-xv). Cambridge, UK: Cambridge University Press. http://dx.doi.org/10.1017/CBO9780511763205.001

*Kaya, Ö. (2006). The addition of creativity in the drama supported education at the third classes art lessons. (Unpublished master's thesis). Gazi University, Ankara, Turkey.

*Kaya, H. İ. (2010). Effects of the practices based on constructivist learning in teacher education on teacher candidates' tendencies of problem solving, critical thinking and creative thinking. (Unpublished doctoral dissertation). Atatürk University, Erzurum, Turkey.

Kayahan, Z. (2010). The creativity of the method of storytelling during the lesson of the educatin of visual arts fifth 
grade students of primary education. (Unpublished master's thesis). Gazi University, Ankara, Turkey.

Kiener, M., \& Ahuna, K. (2011). Creativity as a disposition. In H. Blythe, \& C. Sweet (Eds.), It works for me, creatively: Shared tips for the classroom (pp. 111-112). Stillwater, OK: New Forums Press.

Kim, S. H., \& Kim, S. (2010). The effects of mathematical modeling on creative production ability and self-directed learning attitude. Asia Pacific Educ. Rev., 11, 109-120. DOI 10.1007/s12564-009-9052-x. (EE3).

*Kök, B. (2012). The effect of differentiated geometry teaching on gifted and talented students in view of creativity, spatial ability and success. (Unpublished doctoral dissertation).İstanbul University, İstanbul, Turkey.

Lipsey, M. W., \& Wilson, D. B. (2001). Practical meta-analysis.Thousand Oaks, CA: Sage.

Mayer, R. E. (1999). Fifty years of creativity research. In R. J. Sternberg (Ed.), Handbook of creativity. New York: Cambridge University Press.

Miles, M. B., \& Huberman, A. M. (1994). Qualitative data analysis, 2nd Ed., Newbury Park, CA: Sage.

Moran, S. (2010). The roles of creativity in society. In J. C. Kaufman \& R. J. Sternberg (Eds.),The Cambridge handbook of creativity (pp. 74-90). Cambridge, UK: Cambridge University Press. http://dx.doi.org/10.1017/CBO9780511763205.006

Naeini, F. H., \& Masood, M. (2012). Effect of educational computer games on student creativity. Research Journal of Applied Sciences, Engineering and Technology 4(23), 5280-5284.

Newell, A., Shaw, J., \& Simon, H. (1962). The processes of creative thinking. In H. Gruber, G. Terrell, \& M. Wertheimer (Eds.), Contemporary approaches to creative thinking (pp. 63-119). New York: Atherton. http://dx.doi.org/10.1037/13117-003

Nickerson, R. S. (1999). Enhancing Creativity. In R. J. Sternberg (Ed.), Handbook of creativity, (pp. 392-430). New York: Cambridge University Press.

*Özcan, S. (2009). The effects of creative thinking activities on learners'creative thinking and project development skills. (Unpublished master's thesis)., Gazi University, Ankara, Turkey.

Parker, J. S. (2008). The impact of visual art instruction on student creativity. Doctoral Study Submitted in Partial Fulfillment of the Requirements for the Degree of Doctor of Education Teacher Leadership. Walden University.

Petrowski, M. J. (2000). Creativity research: Implications for teaching, learning, and thinking. Reference Services Review, 28(4), 304-312. http://dx.doi.org/10.1108/00907320010359623

Richards, R. (1999). The subtle attraction: Beauty as a force in awareness, creativity and survival. In S.W. Russ (Ed.) Affect, creative experience and psychological adjustment. Philadelphia, PA: Brunner/Mazel.

Runco, M. A. (2004). Personal creativity and culture. In S. Lau, A.N.N. Hui, \& G.Y.C. Ng (Eds.), Creativity when east meets west. New Jersey: World Scientific. http://dx.doi.org/10.1142/9789812567192_0002

Saç, N. (2011). The effects of creative thinking activities on the creative web design of the elementary school students. (Unpublished master's thesis). Sakarya University, Sakarya, Turkey.

Saiz, C., \& Rivas, S. (2011). Evaluation of the ARDESOS program: An initiative to improve critical thinking skills. Journal of the Scholarship of Teaching and Learning, 11(2), 34-51.

*Sak, U., \& Öz, Ö. (2010). The effectiveness of the Creative Reversal Act (CREACT) on students' creative thinking. Thinking Skills and Creativity, 5, 33-39. http://dx.doi.org/10.1016/j.tsc.2009.09.004

*Sayg11, S. (2008). The effect of analogy-enhanced teaching on mathematical success and creative thinking ability of 9th high school students. (Unpublished master's thesis). Çanakkale Onsekiz Mart University, Çanakkale, Turkey.

Scholl, R. (2005). Student questions: Developing critical and creative thinkers. Thinking, 17(4), 34-46.

Starko, A. J. (2005). Creativity in the classroom: Schools of curious delight (3rd ed.).Mahwah, NJ: Lawrence Erlbaum Associates.

Şahintürk, Ö. (2012). The effect of Montessori method on creativity of the preschool student education. . Unpublished master's thesis. Karaelmas University, Zonguldak, Turkey.

Tezci, E. (2002). The Effects of constructivist instructional design on the success and creativity of fifth-year students in primary schools. (Unpublished doctoral dissertation). Firat University, Elazı̆̆, Turkey.

Thalheimer, W., \& Cook, S. (2002). How to calculate effect sizes from published research articles: A simplified methodology. A part of book. http://education.gsu.edu/coshima/EPRS8530/Effect_Sizes_pdf4.pdf 
Tok, E. (2008). The effects of thinking skills education on the critical, creative thinking and problem solving skills of preschool teacher candidates. (Unpublished doctoral dissertation). MarmaraUniversity, İstanbul, Turkey.

Tomlinson, C. A. (1995). Deciding to differentiate instruction in the middle school: One school's journey. Gifted Child Quarterly, 39(2), 77-114. http://dx.doi.org/10.1177/001698629503900204

Tomlinson, C. A., \& Edison, C. C. (2003). Differentiation in practice: A resource guide for differentiating curriculum grades K-5. Alexandria, VA: Association for Supervision and Curriculum Development.

Torrance, E. P. (1986). Are children becoming more creative? Journal of Creative Behavior, 21(1), 1-13. http://dx.doi.org/10.1002/j.2162-6057.1986.tb00412.x

Treffinger, D. J. (1985). Review of Torrance Tests of Creative Thinking. In J. V. Mitchell (Ed.), Ninth mental measurements yearbook, Vol. II (pp. 1632-1634). Lincoln, NB: Buros Institute of Mental Measurement.

*Uysal, M. E. (2009). The effects of Cooperative learning Method on the access, achievment, critical thinking and creativity skills of the elementary school fourth-grade students. (Unpublished doctoral dissertation). Dokuz Eylül University, İzmir, Turkey.

*Ülger, K. (2011). The effect of problem based learning method to creative thinking in visual arts education. (Unpublished doctoral dissertation). Gazi University, Ankara, Turkey.

Yıldız, Z. (2012). The effect of project based learning approach to high school students' level of creative thinking, problem solving, taking academic risk. (Unpublished master's thesis). Gazi University, Ankara, Turkey.

Y1lmaz, O. (2006). The effects of project based learning on the learners' academic achievement, creativity and attitude at social studies in the 7th grade of primary school. (Unpublished master's thesis). Karaelmas University, Zonguldak, Turkey.

Wang, J. H. T. (2003). The effects of a creative movement program on motor creativity and gross motor skills of preschool children. Division of Educational Administration Adult and Higher Education Program in the Graduate School, the University of South Dakota, United States.

\section{$(\mathrm{Cc}) \mathrm{BY}$}

This work is licensed under a Creative Commons Attribution 3.0 License. 